\title{
Experimental Research on the Impact of Interface Temperature on the Adhesion Properties of Clay under the Condition of Different Contacting Time
}

\author{
Tao Qiu $\mathbb{D}^{1}$ and Yonggang Zhang $\mathbb{D}^{2}$ \\ ${ }^{1}$ School of Civil Engineering, Nanjing Forestry University, Nanjing, Jiangsu Province 210037, China \\ ${ }^{2}$ Key Laboratory of Geotechnical and Underground Engineering of Ministry of Education, and Department of \\ Geotechnical Engineering, Tongji University, Shanghai 200092, China
}

Correspondence should be addressed to Tao Qiu; qt@njfu.edu.cn and Yonggang Zhang; demonzhangyg@tongji.edu.cn

Received 24 May 2021; Accepted 30 July 2021; Published 27 August 2021

Academic Editor: José Luis Pastor

Copyright (c) 2021 Tao Qiu and Yonggang Zhang. This is an open access article distributed under the Creative Commons Attribution License, which permits unrestricted use, distribution, and reproduction in any medium, provided the original work is properly cited.

\begin{abstract}
Mud cakes are very likely to occur at the shield cutter when the shield machine passes through a clay stratum, which adhere to the cutter and reduce the excavation efficiency. Due to the thrust of the cutter, the mud cakes are compacted and cause friction at the soil-structure interface, which results in high temperature and aggravates the adhesion, and the effect tends to become stronger as the heating process lasts. In this paper, the effects of the interface temperature and the contacting time between the soil and the hot surface on the adhesion properties of the soil were studied by a self-made adhesion test device. According to the findings, at low interfacial temperature $\left(\leq 40^{\circ} \mathrm{C}\right)$, both the adhesion force and the amount of adhered soil were insignificant in a short term, and the effects were found to be strengthened as the contacting time went on; at the high interfacial temperature $\left(\geq 50^{\circ} \mathrm{C}\right)$, very significant soil adhesion occurred at the structure surface within a short time, and as the contacting time increased, the amount of the adhered soil decreased rapidly while the adhesion force kept increasing, and both tended to remain a constant and become independent with the temperature after a long-term contact. This study is of guiding significance for understanding the formation and development of the shield mud cakes during shield construction.
\end{abstract}

\section{Introduction}

With the development of China's social economy and the improvement of people's living quality, subway, as a safe, fast, efficient, and environmentally friendly form of transportation, has become the first choice of many urban masses to travel $[1-3]$. When excavating the subway tunnels, the shield construction method is widely used, which has the characteristics of rapid construction, low noise, vibration, and environmental pollution. Meanwhile, the method can reduce the impact on urban traffic, overground buildings (or structures) and people's production activities during the construction.

However, when shield tunnelling is used in complex stratums, especially in a stratum rich of clay mineral parti- cles, such as the clay stratum and the mudstone stratum, the construction problem of shield mud cake is often encountered. When the phenomenon of shield mud cake occurs, the cutter head is usually wrapped by clay soil, which can decrease the cutter penetration during shield excavation and lead to a significant decrease in the construction efficiency. Serious mud cake can cause a series of adverse effects, including mud pipe blocking and rotation torque increase of the cutter head which further results in large fluctuation of shield parameters [4-7]. If proper treatment measures are not taken, the mud cake can become more and more dense under the action of the cutter head thrust, causing both the oil cylinder thrust and the cutter head rotating moment to increase. In addition, high temperature can occur on the surface of the cutter head due to friction [8-11], which 


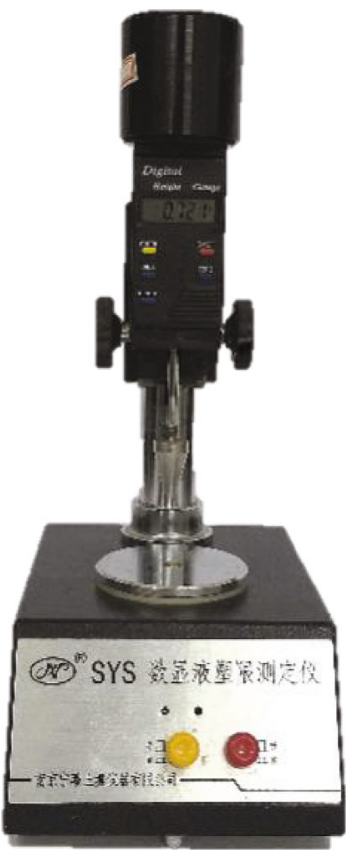

(a) Liquid-plastic limit tester

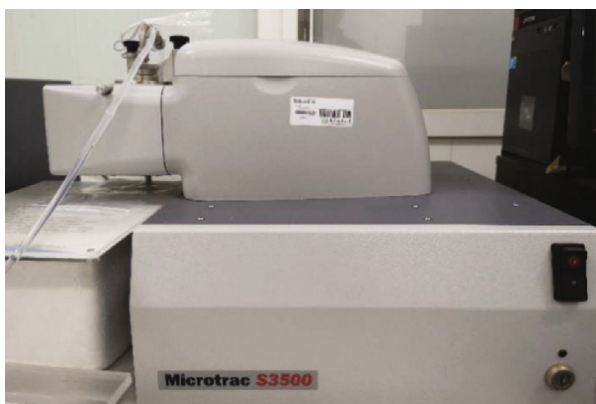

FIgURE 1: Soil property testing equipment.

enhances the soil adhesion, and the situation becomes even worse if water migration occurs to the soil on the excavated face [12-16].

\section{Materials and Methods}

2.1. Experiment Samples. In order to solve a series of problems encountered in the shield tunnelling process of Nanjing subway tunnel, the clay soil samples taken from the construction section of the North Extension Project of Nanjing Metro Line 1 (No. D1N-TA04) were studied in this paper.

According to the Standard for Soil Test Methods (GB/T50123-2019), the liquid and plastic limit tester SYS-2 (Figure 1(a)) was adopted to determine the plastic limit and liquid limit of the soil samples tested in this paper. Five kinds of soil samples with moisture content of $25 \%, 30 \%$, $35 \%, 40 \%$, and $45 \%$ were prepared and tested. Each sample was $200 \mathrm{~g}$. The soil samples were wrapped in plastic film and placed for 24 hours. After the soil moisture migration is sufficient, each soil sample was layered and densely filled into the sample cup with a geotechnical knife. The liquid and plastic limits of the soil samples were tested by the tester mentioned above. The measured plastic limit $w_{P}$ was $21.21 \%$, the liquid limit $w_{L}$ was $37.5 \%$, and the plastic index $I_{P}=16.29$. According to the Code for Investigation of Geotechnical Engineering (GB50021-2018) standard, the test soil was determined to be silty clay.

The laser particle size analyzer (Figure 1(b)) was used to analyze the particle size distribution of the soil samples, and the obtained grain size distribution curve is shown in Figure 2. It can be seen from the figure that the diameter range of the tested soil is mainly between $10 \mu \mathrm{m}$ and $300 \mu \mathrm{m}$, and the particles greater than $300 \mu \mathrm{m}$ and less than

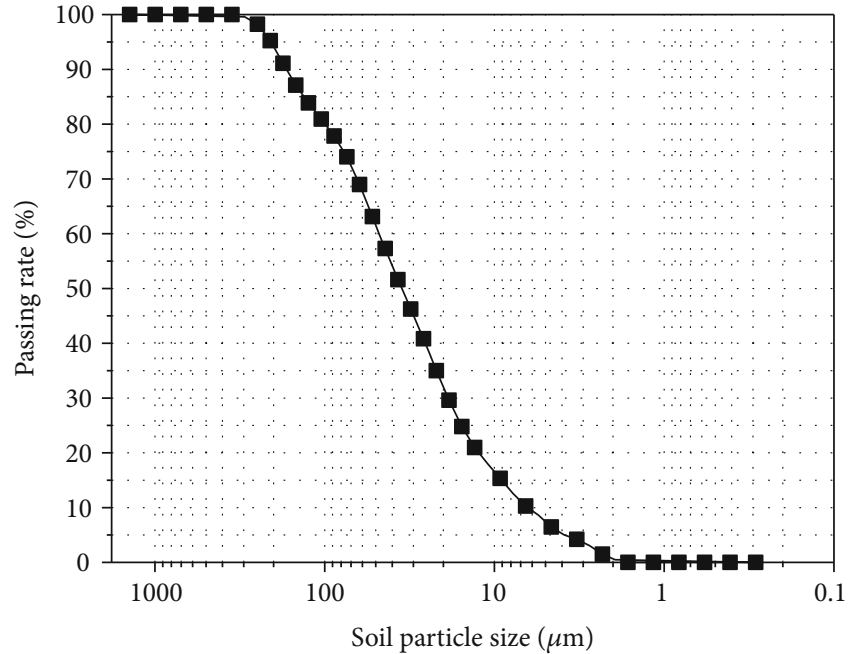

FIgURE 2: Grain size distribution curve of used clay soil sample [17].

Table 1: Physical parameters of used clay soil sample [17].

\begin{tabular}{lccccc}
\hline $\begin{array}{l}\text { Plastic } \\
\text { limit } \\
(\%)\end{array}$ & $\begin{array}{c}\text { Liquid } \\
\text { limit } \\
(\%)\end{array}$ & $\begin{array}{c}\text { Nonuniform } \\
\text { coefficient }\end{array}$ & $\begin{array}{c}\text { Dominant } \\
\text { diameter } \\
(\mu \mathrm{m})\end{array}$ & $\begin{array}{c}\text { Silt } \\
\text { particle } \\
\text { content } \\
(\%)\end{array}$ & $\begin{array}{c}\text { Clay } \\
\text { particle } \\
\text { content } \\
(\%)\end{array}$ \\
\hline 21.26 & 37.5 & 7.52 & 47.87 & 66.92 & 7.38 \\
\hline
\end{tabular}

$10 \mu \mathrm{m}$ take up less than $10 \%$, which is a small proportion. The main part of the particle grading curve fits well with an inclined straight line, which indicates the soil particle size distribution is relatively uniform and the soil particle 


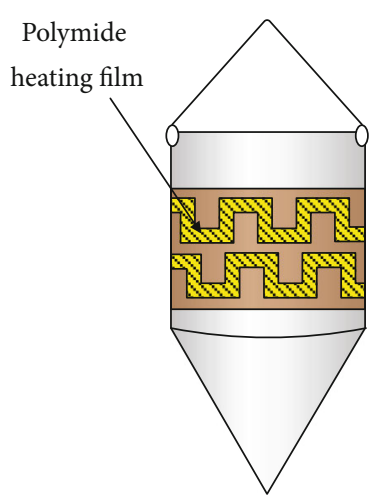

(a) External structure

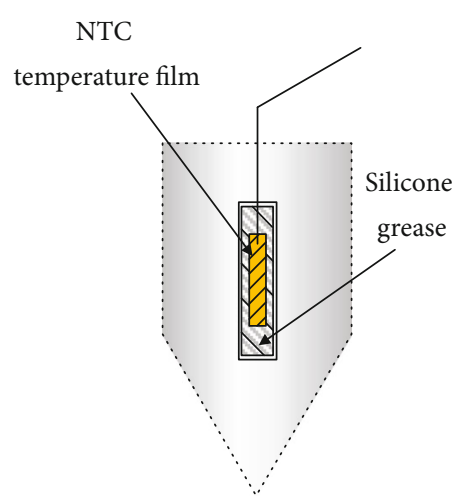

(b) Internal structure

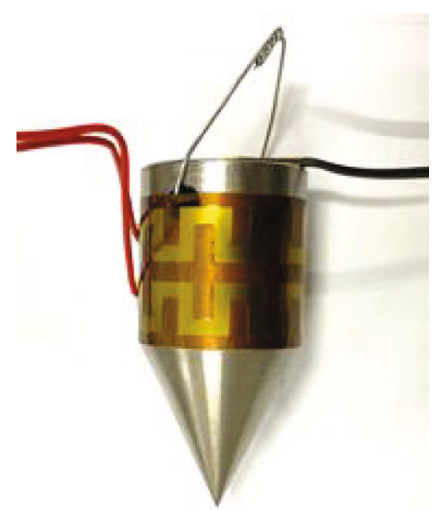

(c) Physical diagram

Figure 3: Schematic diagrams and a photo of the test cone.

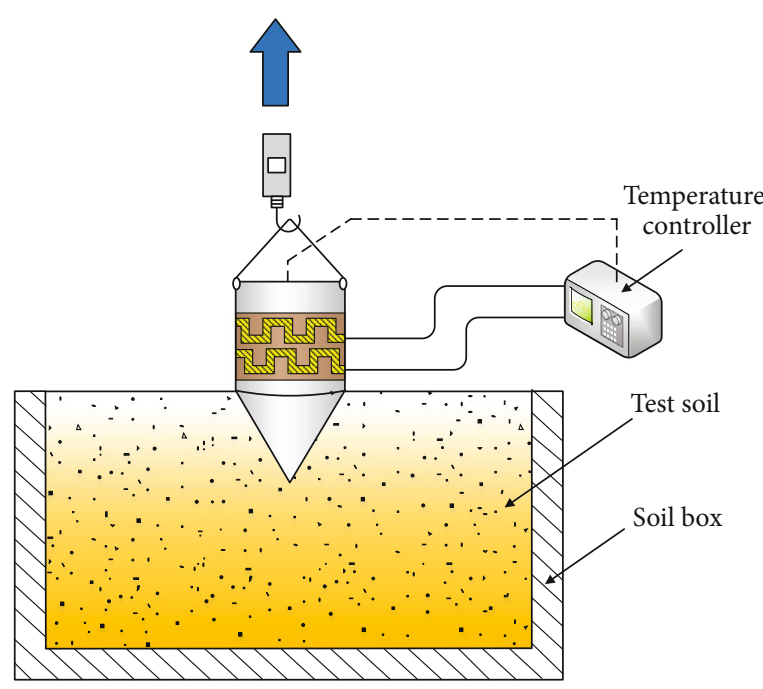

(a) Schematic diagram

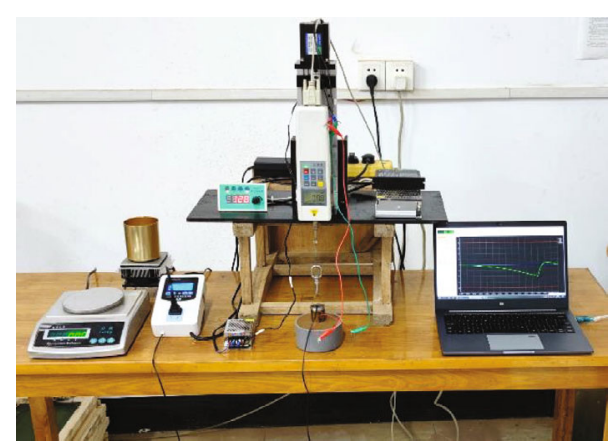

(b) Physical diagram

FIgURE 4: Experiment set-up of the adhesive test.

content in each particle size range is close to each other. The physical parameters of soil obtained from the above tests are summarized in Table 1.

2.2. Experiment Apparatus. As shown in Figure 3, we made a steel cone as the soil contact part by referring the method adopted by other investigators $[18,19]$, which contains a cylinder part at top and a $54.4^{\circ}$ cone part at the bottom. The cone part is in contact with the soil and has a negative temperature coefficient (NTC) temperature sensor inside, and the upper cylinder part is wrapped with a ring of polyimide heating film to heat the test cone.

Owing to the design above, the adhesion test device enables the interface temperature controllable, and the experiment set-up is shown in Figure 4. The polyimide heating film wrapped on the upper part of the cone can heat the test cone stably and rapidly, and the heating film is powered by an external temperature controller via a $12 \mathrm{~V}$ variable voltage. The temperature control power collects the temperature of the test cone in real time. When the temperature of the collected cone is lower than the preset heating temperature, the temperature control power turns on automatically to heat the test cone and vice versa. Hence, the testing cone can be maintained at a relatively stable temperature, and the control system is shown in Figure 5. During the tests, the hanging rope connected to the cone was pulled by a selfmade electric traction device [17] to separate the surface of the testing cone from the soil.

In order to cool the high-temperature test cone quickly after heating, the semiconductor cooling device as shown in Figure 6 was adopted. The device used a semiconductor chilling plate in the center to achieve the cooling purpose, and its top and bottom worked as cold and hot ends, respectively. The hot end was in contact with an aluminium cooling fin placed beneath. A cooling fan was mounted below the cooling fin to continuously absorb the heat. The whole structure was supported by the long screws under the cooling fan. The cold end was in contact with the metal soaking plate to cool the copper cooling cup which contained cooling water inside, and the temperature of the water could be low up 


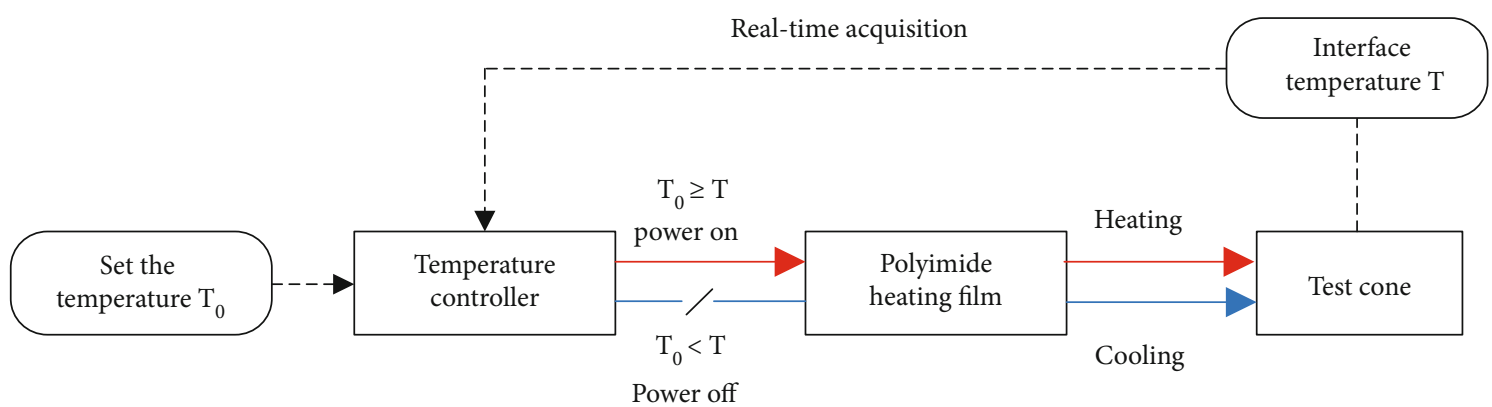

FIGURE 5: Operation principle of the interface temperature control.

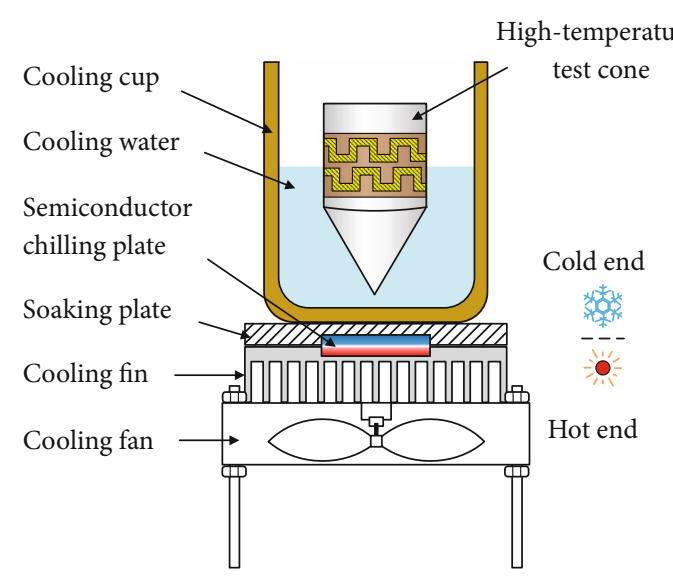

(a) Schematic diagram

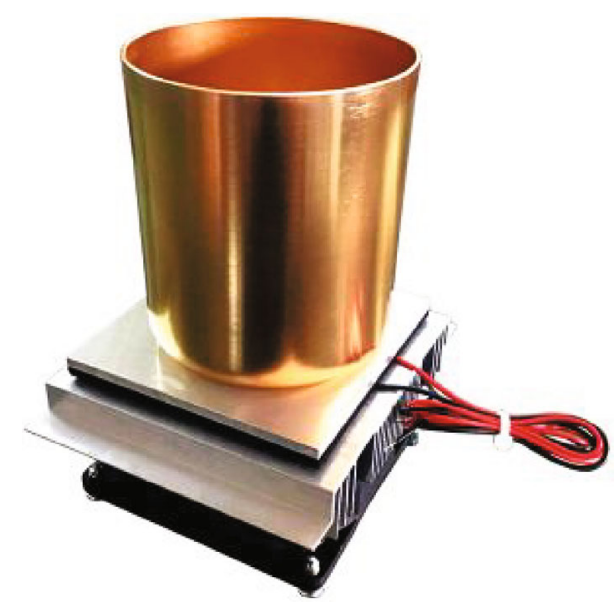

(b) Physical diagram

FIGURE 6: Semiconductor cooling device.

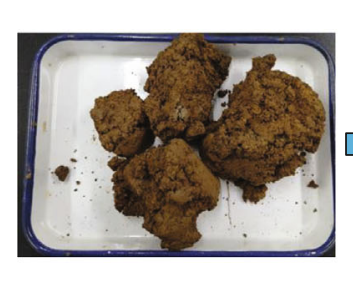

Undisturbed soil

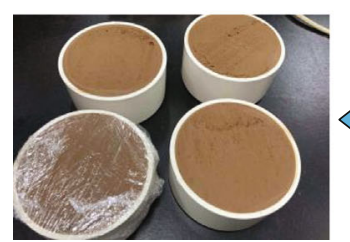

Soil sample preparation

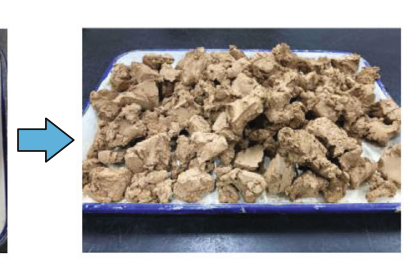

Drying
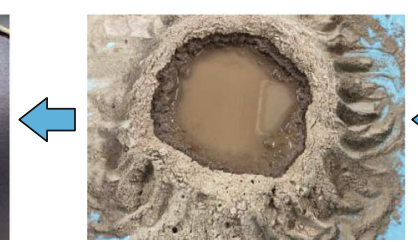

Mixed with water
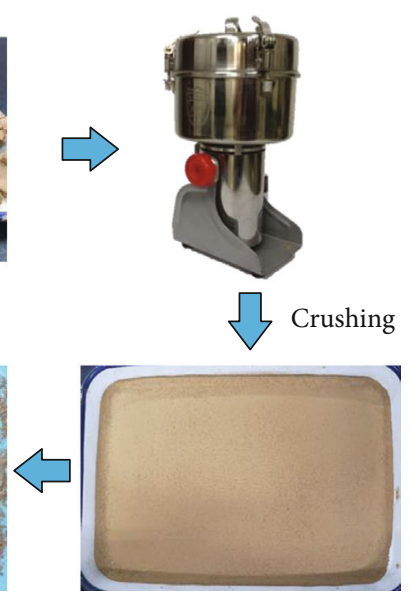

Screening

Figure 7: Preparation of test soil samples.

$2^{\circ} \mathrm{C}$. With the self-made cooling device, the hot cone can be cooled down quickly by simply putting it into in the cooling water, which greatly shortened the time of cooling and improved the test efficiency.

2.3. Soil Sample Preparation. As shown in Figure 7, the undisturbed soil samples taken on site were first placed in a $105^{\circ} \mathrm{C}$ oven to dry for more than 24 hours to ensure that the water in the soil evaporated completely. Then, the dried soil samples were crushed with a small hammer and placed in a soil crusher to be crushed into particles. The crushed soil particles were screened through a $0.5 \mathrm{~mm}$ sieve and collected for use. According to the required soil moisture contents in the test, a certain proportion of pure water was 
correspondingly added to the collected sieved soil particles and stirred evenly. Following the soil paste method [20], the prepared soil was filled into the plastic soil boxes using a geotechnical knife. Each soil box was then wrapped with a plastic film and placed in an indoor dry and ventilated place for 24 hours, waiting for the water in the soil to migrate fully.

2.4. Experiment Design. To study the effect of contacting time on the soil-structure interface adhesion at different temperatures, we selected the soil samples with $23 \%$ moisture content for the tests. The tested interface temperatures were $30^{\circ} \mathrm{C}, 40^{\circ} \mathrm{C}, 50^{\circ} \mathrm{C}, 60^{\circ} \mathrm{C}$, and $70^{\circ} \mathrm{C}$, and the contacting time were $0 \mathrm{~min}, 2 \mathrm{~min}, 4 \mathrm{~min}, 8 \mathrm{~min}, 16 \mathrm{~min}$, and $32 \mathrm{~min}$ (see Table 2). The experiment includes 30 working conditions, and no less than 3 groups of parallel tests are carried out in each working condition.

In each test, the test cone was separated from the soil at a speed of $5 \mathrm{~mm} / \mathrm{min}$. The test steps are as follows:

(1) Press the lower cone part of the test cone into the prepared soil sample vertically and slowly

(2) Connect the hanging rope on the upper part of the test cone with the tension meter on the traction testing device, and set the electronic tension meter to zero

(3) Connect the NTC temperature sensor, check the temperature acquisition status of the temperature controller, and set the heating temperature

(4) Connect the power supply of the electric traction test device, connect the computer to the electronic tension meter through the data acquisition line, and check the operation of the device and data acquisition

(5) Connect the polyimide heating film power supply and start to heat the interface

(6) Once the preset temperature was achieved, start the timing and record the contacting time

(7) Once the preset time was finished, turn on the data acquisition software and the electric traction test device and pull up the test cone at a speed of $5 \mathrm{~mm} / \mathrm{min}$. After the surface of the test cone was completely separated from the test soil sample, finish the data recording and save it

(8) Repeat the test two more times and take the peak tensile force as the measured value of the total adhesion force

(9) Change the heating temperature and repeat the operations above

\section{Results}

3.1. The Relationship between Adhesive Force and Contacting Time. The soil was bonded to the structure surface when they were closely contacted. By exerting an opposite force
TABle 2: Experimental design of effect of contacting time on soil adhesion.

\begin{tabular}{lcc}
\hline $\begin{array}{l}\text { Group } \\
\text { number }\end{array}$ & $\begin{array}{r}\text { Interface temperature } \\
\left({ }^{\circ} \mathrm{C}\right)\end{array}$ & $\begin{array}{c}\text { Contacting time } \\
(\mathrm{min})\end{array}$ \\
\hline 1 & 30 & \\
2 & 40 & $0,2,4$ \\
3 & 50 & $8,16,32$ \\
4 & 60 & \\
5 & 70 & \\
\hline
\end{tabular}

on the contact interface to resist the bonding effect can separate the connection. The required force on the unit area of the contact interface can be called the adhesion force [20], which is expressed by $F$.

$$
F=\frac{p}{A}
$$

where $F$ is the nominal force on the interface that is required to separate the connection and $A$ is the contact area between soil and structure surface.

Adhesion forces under 5 different interface temperatures and 6 contacting periods ranging from $0 \mathrm{~min}$ and $32 \mathrm{~min}$ were tested. Taking the interface temperature as the abscissa and the adhesion force as the ordinate, Figure 8 plots temperature-adhesion force curves using the tested data. As can be seen from the figure, with the increase of the interface temperature, the adhesion forces in a short-term contacting are significantly different from those after a longterm contacting. As the contacting time increases, the curves changed from a concave form to a convex form.

For the tests under short contacting time, the adhesion forces are noticed first decrease and then increase with the increase of the interface temperature. For $0 \mathrm{~min}$ and $2 \mathrm{~min}$ contacts, the adhesive forces at $30^{\circ} \mathrm{C}$ are $5.56 \mathrm{kPa}$ and $5.45 \mathrm{kPa}$, respectively. The adhesive force remains relatively stable until the interface temperature is up to $40^{\circ} \mathrm{C}$. At $50^{\circ} \mathrm{C}$ of interface temperature, the adhesion forces of these two scenarios decrease significantly, and the shorter the contacting time, the more obvious the decrease. Specifically, the adhesion decrease of the $0 \mathrm{~min}$ scenario is $28.7 \%$, while it is only $9.2 \%$ for the 2 min scenario.

When the contacting time is longer than $4 \mathrm{~min}$, the temperature-adhesive force curves are seen first increasing and then remaining stable, and the interface temperature required to maintain stability decreases with the increase of the contacting time. When the contacting time is $4 \mathrm{~min}$, the adhesion force increases with the increase of the interface temperature. When the temperature reaches $60^{\circ} \mathrm{C}$, the adhesion force is $6.91 \mathrm{kPa}$, and the adhesion force remains stable regardless of the increase of the interface temperature. For $8 \mathrm{~min}$ and $16 \mathrm{~min}$ contacts, the adhesion forces remain stable when the interface temperature rises to $60^{\circ} \mathrm{C}$, and the adhesion forces are $7.33 \mathrm{kPa}$ and $7.95 \mathrm{kPa}$, respectively. When the contacting time is relative long, the adhesion force reaches a high level at low interface temperature. For example, when the contact lasts for $32 \mathrm{~min}$, the adhesion force at 


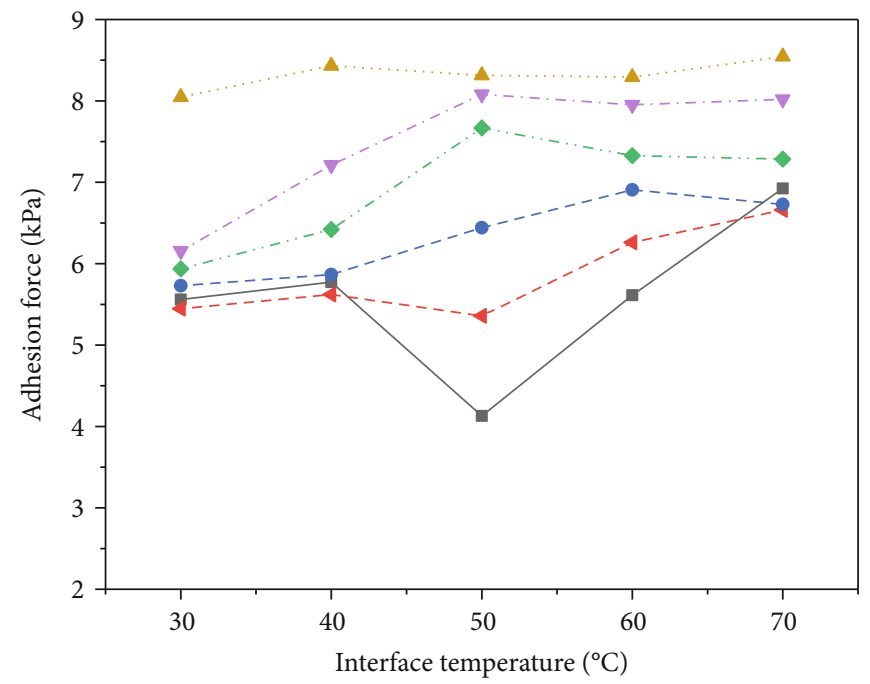

Contacting time

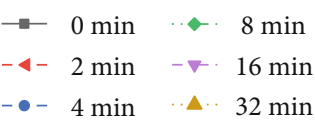

FIGURE 8: The adhesion force changes with interface temperature.

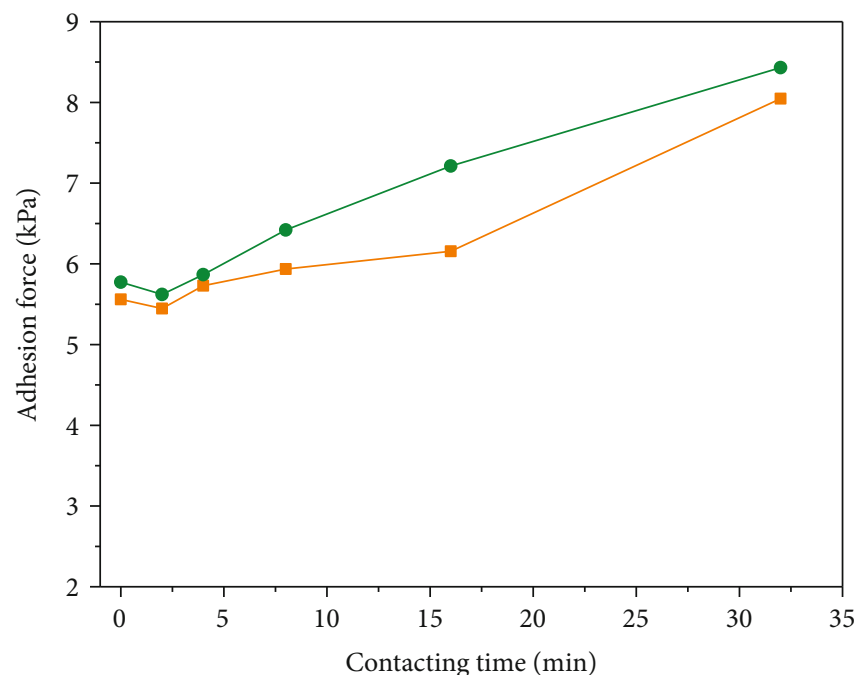

Interface temperature

$\rightarrow 30^{\circ} \mathrm{C}$

$\rightarrow 40^{\circ} \mathrm{C}$

(a) Relative low interface temperature

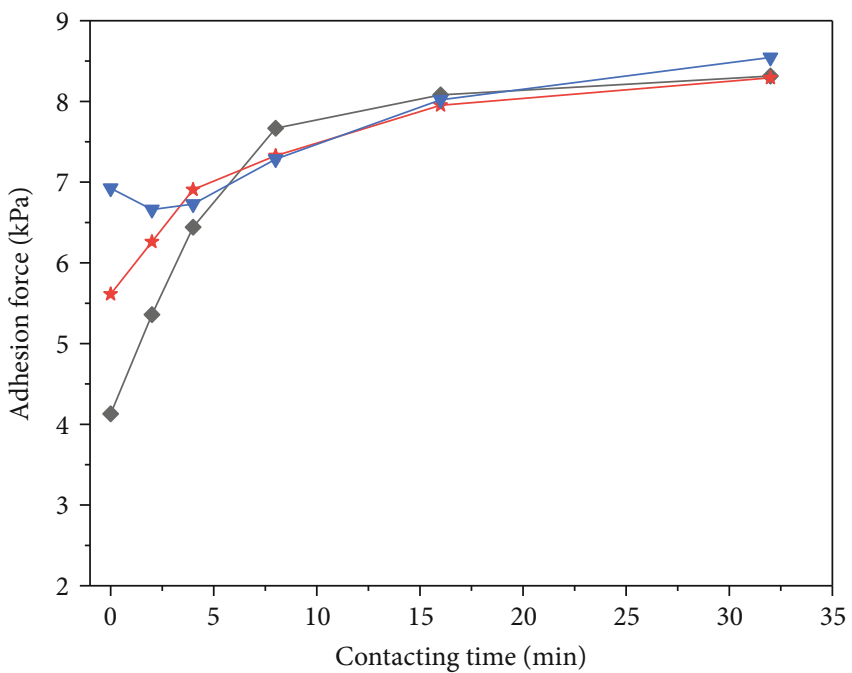

Interface temperature

$\rightarrow 50^{\circ} \mathrm{C}$
$\leftarrow \quad 60^{\circ} \mathrm{C}$
$\rightarrow \quad 70^{\circ} \mathrm{C}$

(b) Relative high interface temperature

FIgure 9: Adhesion force changes with contacting time.

the interface temperature of $30^{\circ} \mathrm{C}$ is $8.0 \mathrm{kPa}$, which is only $0.5 \mathrm{kPa}$ less than that of the $70^{\circ} \mathrm{C}$ case.

In Figure 9, the contacting time is taken as the abscissa and the adhesion force is used as the ordinate to analyze each temperature group test. When the interface temperature is low $\left(30^{\circ} \mathrm{C}\right.$ and $\left.40^{\circ} \mathrm{C}\right)$ and the contacting time is short, the adhesion forces are close and grow with the contacting time, and the higher the interface temperature, the faster the growth. When the interface temperature is high $\left(\geq 50^{\circ} \mathrm{C}\right)$ and the contacting time is short, the higher the interface temperature, the greater the adhesion force. Specifically, when the interface temperature is $50^{\circ} \mathrm{C}$, the adhesive force is $4.13 \mathrm{kPa}$, and when the interface temperature is $60^{\circ} \mathrm{C}$, the adhesive force increases to $5.61 \mathrm{kPa}$. When the interface temperature is up to $70^{\circ} \mathrm{C}$, the adhesive force increases to $6.92 \mathrm{kPa}$, and the increase rate of the adhesion 


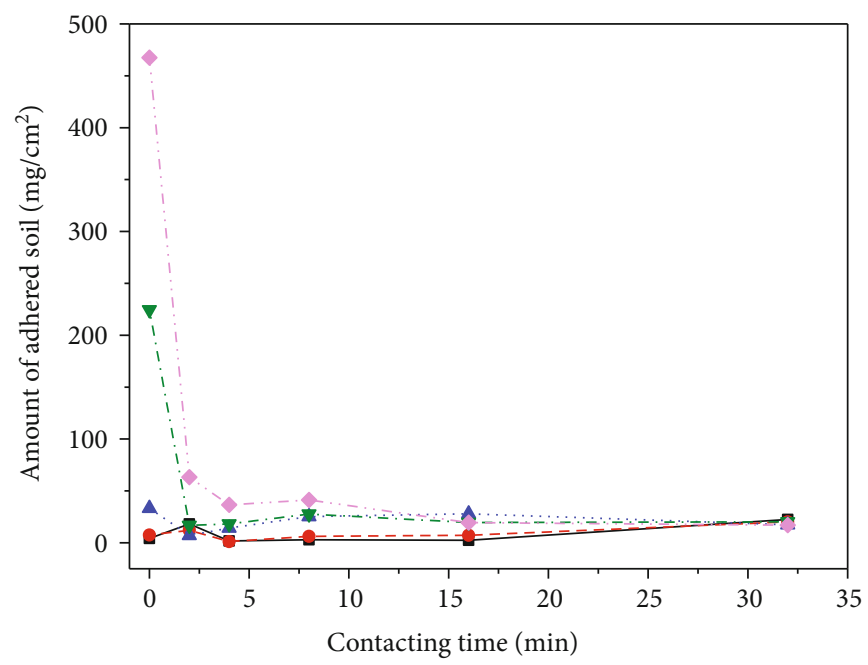

Interface temperature
$\rightarrow-30^{\circ} \mathrm{C} \quad \rightarrow-60^{\circ} \mathrm{C}$
$--40^{\circ} \mathrm{C} \quad-\quad 70^{\circ} \mathrm{C}$
$\cdots \quad 50^{\circ} \mathrm{C}$

FIgURE 10: The relationship between the contacting time and the amount of adhered soil.

force gradually decreases with the increase of contacting time. When the contacting time reaches $16 \mathrm{~min}$, the value of adhesion force tends to reach around $8.02 \mathrm{kPa}$.

3.2. Soil Adhesion at the Surface. The residual soil on the surface of the structure per unit area after applying the separation force $F$ was taken as the amount of adhered soil, which can be expressed by $m$.

$$
m=\frac{M}{A},
$$

where $M$ is the total amount of residual soil and $A$ is the contact area between soil and structure surface.

As shown in Figure 10, the relationship between the amount of adhered soil and the contacting time was analyzed. For a given contacting time, the amount of soil adhered to the surface increases with the increase of the interface temperature, and the form of the soil adhesion gradually changes from a local agglomerate adhesion at low interface temperature to a large area adhesion at high interface temperature (see Figure 11). Among them, the most significant change happens to the scenario where the contacting time is 0 . When the interface temperature increases from $30^{\circ} \mathrm{C}$ to $50^{\circ} \mathrm{C}$, the amount of adhered soil increases slowly from the low point of $4.3 \mathrm{mg} / \mathrm{cm}^{2}$. After the interface temperature rises above $50^{\circ} \mathrm{C}$, the amount of adhered soil starts to increase obviously, and the magnitude reaches $467.5 \mathrm{mg} / \mathrm{cm}^{2}$ which is 110 times of that of the $30^{\circ} \mathrm{C}$ case.

In Figure 12, we plot the relationship between the contacting time and the amount of adhered soil. It can be seen that the contacting time has various effects on the soil adhesion when the surface is heated. When the contacting time is
$2 \mathrm{~min}$ to $4 \mathrm{~min}$, the amount of adhered soil at the heated surface decreases for all temperature scenarios but the effect varies from one to another. Among them, obvious decreases happen to the surfaces with high temperature $\left(\geq 60^{\circ} \mathrm{C}\right)$, and the decrease shows little reaction to the increase of contacting time. The soil adhesion at the interface of $70^{\circ} \mathrm{C}$ decreased from $467.5 \mathrm{mg} / \mathrm{cm}^{2}$ to $36.6 \mathrm{mg} / \mathrm{cm}^{2}$ when the contacting time increases from $0 \mathrm{~min}$ to $4 \mathrm{~min}$, with a reduction of $92.2 \%$. After that, the soil adhesion tends to decrease slowly, with a reduction of $19.6 \mathrm{mg} / \mathrm{cm}^{2}$ after a followed $28 \mathrm{~min}$ heating process. The observed decrease trend of the $60^{\circ} \mathrm{C}$ case is similar, and the adhered soil decreases rapidly from $131.2 \mathrm{mg} / \mathrm{cm}^{2}$ to $16.8 \mathrm{mg} / \mathrm{cm}^{2}$ during the first 4 min heating process, with a reduction of $87.2 \%$ and then tends to become stable. For interfaces with relatively low interface temperatures, like $30^{\circ} \mathrm{C}, 40^{\circ} \mathrm{C}$, and $50^{\circ} \mathrm{C}$, the effect of the contacting time on the soil adhesion is seen insignificant.

\section{Discussion}

When water is in contact with the surface of soil particles and structural surfaces, due to the interaction between the force field on the solid surface and water molecules, the structure of the adjacent water stabilizes and forms a water film, that is, compared with the liquid water at the same temperature, the bonding structure of the adjacent water increases and the energy decreases [21]. Assuming there is a layer of water film $j$ between solid surfaces $i$ and $k$, and its thickness is $D$, then one can approximately consider that the potential energy $U$ of the interface interaction between surfaces $i$ and $k$ on water film $j$ is [22] as follows:

$$
U=-\frac{\pi f}{12} N_{j}\left[N_{i} C_{i j} d^{-2}+N_{K} C_{K j}(D-d)^{-2}\right]
$$




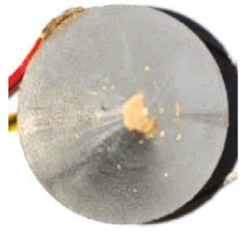

0 min

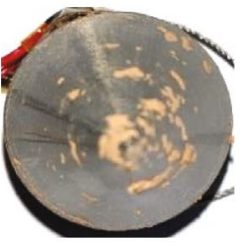

0 min

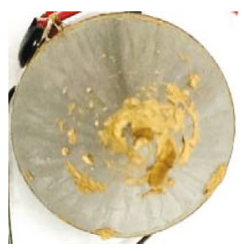

0 min

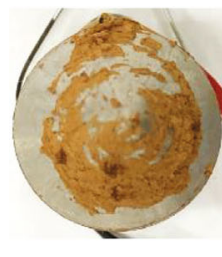

0 min

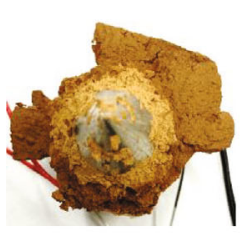

0 min

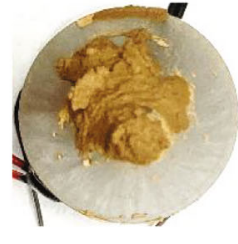

2 min

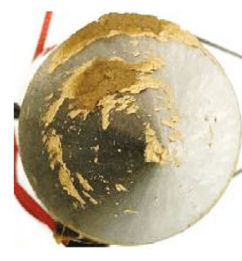

$2 \min$

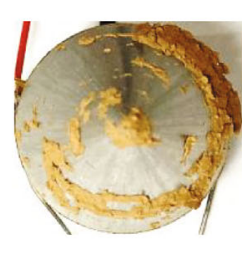

$2 \min$

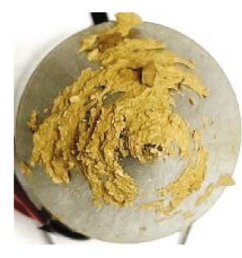

$2 \min$

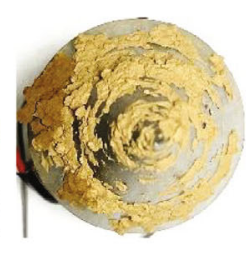

$2 \min$
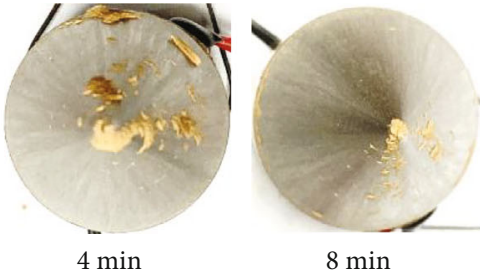

(a) $30^{\circ} \mathrm{C}$

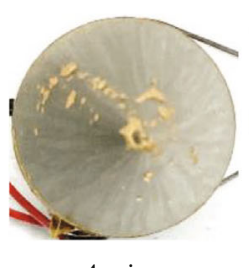

$4 \mathrm{~min}$

(b) $40^{\circ} \mathrm{C}$
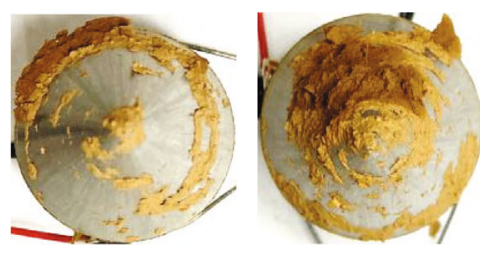

$8 \mathrm{~min}$

(c) $50^{\circ} \mathrm{C}$
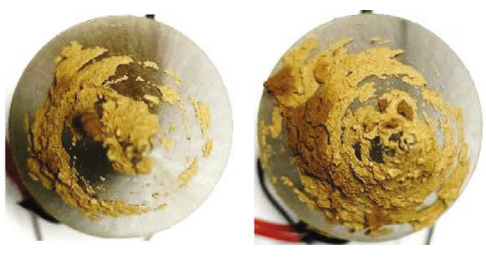

$8 \mathrm{~min}$

(d) $60^{\circ} \mathrm{C}$
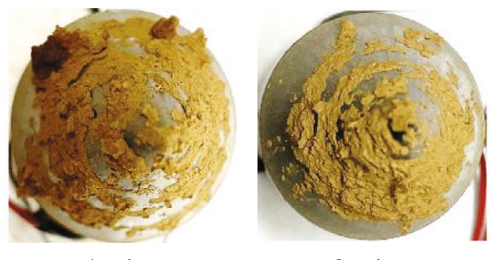

$8 \mathrm{~min}$

(e) $70^{\circ} \mathrm{C}$
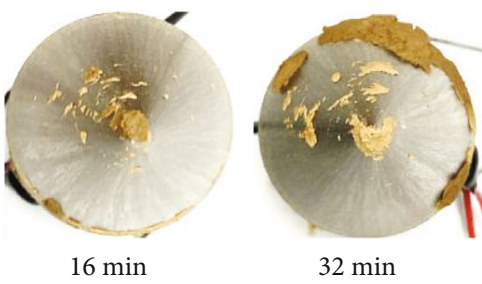

$32 \mathrm{~min}$

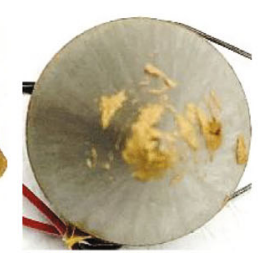

$16 \mathrm{~min}$

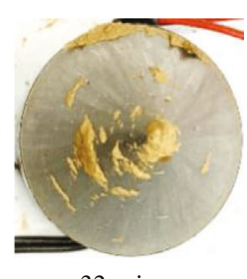

$32 \mathrm{~min}$

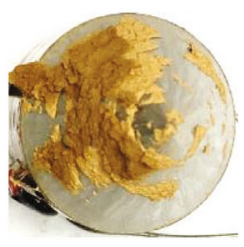

$16 \mathrm{~min}$

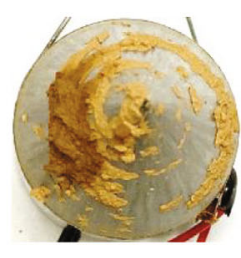

$32 \mathrm{~min}$

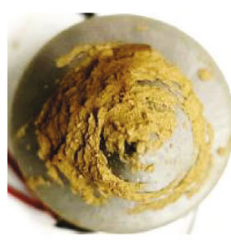

$16 \mathrm{~min}$

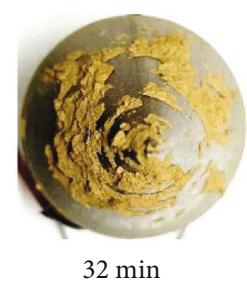

$32 \mathrm{~min}$

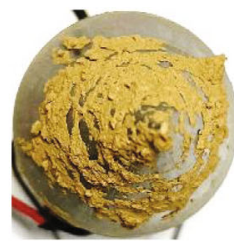

$16 \mathrm{~min}$

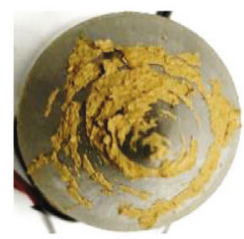

$32 \mathrm{~min}$

FIgURE 11: The condition of soil adhering to surface.

where $d$ is the distance from the surface $i, f$ is the coefficient of repulsive energy considering molecular approach, $C$ is the interaction coefficient between molecules, and $N_{i}$ and $N_{j}$ are the number of volume elements per unit volume in the two interfaces.

Considering Equation (3), there is always a certain $d$ that minimizes the interface interaction potential energy. The layer determined by the very $d$ has the highest energy in the water film and is called the "high-energy layer" (see Figure 13). The energy input needed to destroy the "highenergy layer" is smaller than that of other layers, so the destruction always occurs from the "high-energy layer." The state of the "high-energy layer" determines the cohesion and adhesion of the soil.

The stripping plane of the soil adhesion, i.e., the weakest antistripping plane, consists of a series of "high-energy layers." Temperature can change the moisture content of the soil within the influence range of the interface, and the heat conduction has an effect on the moisture energy of the soil, which subsequently affects the position and energy of the "high-energy layer" and changes the position of the weakest antistripping plane and the required energy. On 


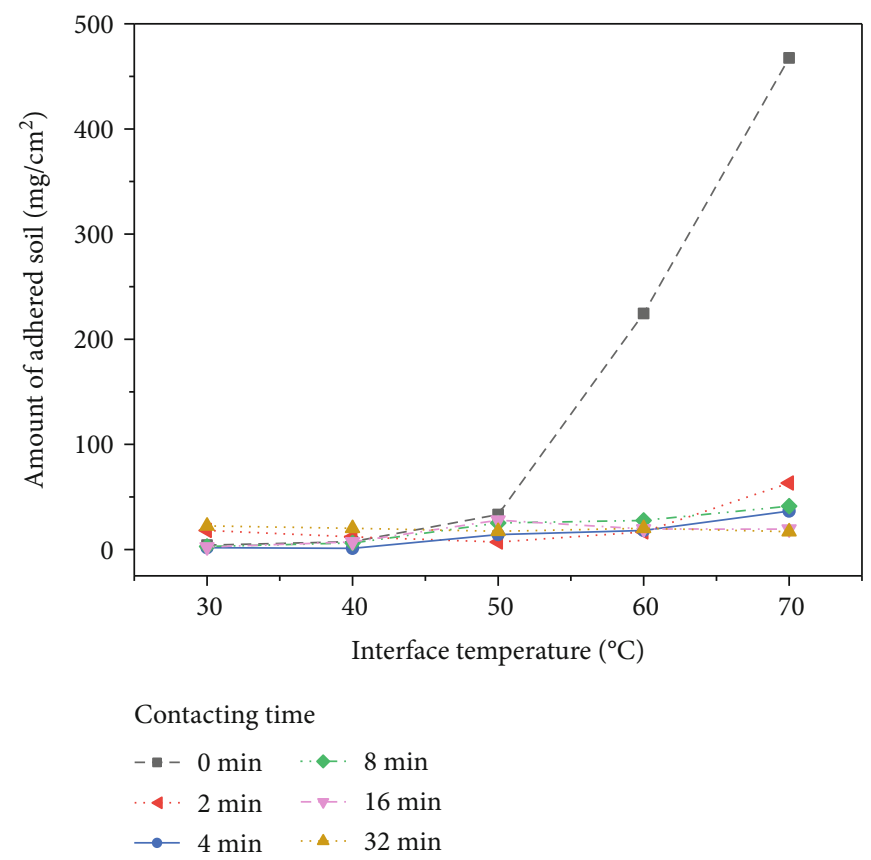

Figure 12: The relationship between the interface temperature and the amount of adhered soil.

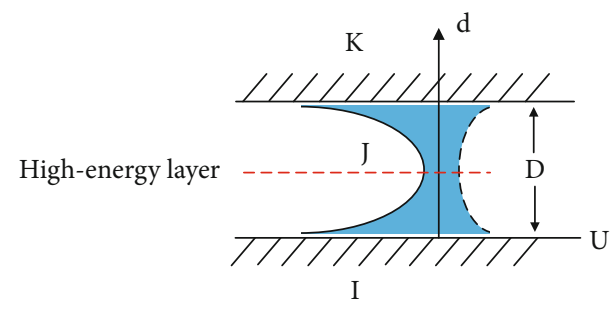

FIGURE 13: Potential energy distribution in water films on two solid surfaces.

the other hand, the contacting time determines the heating process and therefore also affects the water content and energy.

When the interface temperature is low, the soil temperature gradient is not high, causing the soil moisture and energy within the interface to change little in a short time. Hence, its influence on the adhesion force and viscosity allowance is limited. With the increase of the contacting time, the soil moisture migration at the interface appears, and the soil moisture at the interface gradually decreases with the contacting time, causing the cohesion and adhesion forces to increase gradually. For a short-term contact, the soil moisture decrease is limited due to the low temperature gradient, which also results in limited increase of cohesion and adhesion forces. In this situation, the weakest antistripping plane is likely to occur in a limited range of soil near the adhesion interface, and the observation is the adhesion force increases and more adhered soil appears.

When the interface temperature is high, the temperature difference between the structure surface and the soil is large, and the water migration caused by the temperature gradient is obvious. The water content of the soil near the interface decreases rapidly in a short time, leading the cohesion and adhesion forces to increase rapidly. On the other hand, due to a short contacting time, the moisture migration range is limited. In this situation, the soil near the interface has low moisture content and high cohesion and adhesion forces, while the outer soil has relatively large moisture content and low cohesion force. Therefore, the weakest antistripping plane occurs in the outer soil, which results in significant soil adhesion. With the increase of contacting time, more reduction of water content of the soil near the interface occurs, causing the cohesion of the surrounding soil to increase. In addition, the soil layer close to the interface has the highest temperature and lowest moisture, which makes it subject to relatively strong external adhesion force and causes the tight adhesion. In this situation, the weakest antistripping plane tends to move toward the interface, causing the outer soil mass to strip, which results in the observation of rapid soil adhesion reduction in a short time. When the contacting time is long, more obvious decrease of water content occurs to the soil near the interface, which strengths the cohesion of the surrounding soil. At this time, the weakest antispalling plane locates between the interface layer and the outer soil and remains stable regardless of the contacting time increase. Therefore, the adhesion force between the interface layer and the outer soil plays an important role in this situation, and the observation is the amount of adhered soil tends to become independent with the contacting time and the temperature.

\section{Conclusions}

The temperature influences the interfacial adhesion characteristics by mechanisms of soil moisture content change and energy increase, and the contacting time between the soil and the hot structure surface also plays an important role. The main findings are as follows: 
(1) At low interface temperature, the effects of the interface temperature on soil adhesion are limited if the contacting time is short. When increasing the contacting time, both the adhesion force and the amount of adhered soil are observed to increase slightly

(2) At low interface temperature, significant soil adhesion occurs even in a short contacting time. When increasing the contacting time, the adhered soil decreases rapidly in a short period of time while the adhesion force tends to increase. After a longterm contact, both the adhesion force and amount of adhered soil become relatively stable and independent with the temperature

Therefore, in order to mitigate the soil adhesion effect on the shield cutter head and reduce the occurrence of mud cake, it is necessary to ensure a relatively low temperature at the interface between the cutter head and the soil on the excavation face. Also, it should be helpful to speed up the excavation, which reduces contacting time between the hot structure surface and the soil.

\section{Data Availability}

The data are generated from experiments and can be available from the corresponding author upon request.

\section{Conflicts of Interest}

The authors declare that there are no conflicts of interest regarding the publication of this paper.

\section{Authors' Contributions}

Tao Qiu carried out the experiments, analyzed the results, and conducted the theoretical explanations, as well as wrote the manuscript. Yonggang Zhang provided constructive suggestions and performed significant review and editing of the technical paper, as well as provided rigor and fluency in the language of the academic paper.

\section{Acknowledgments}

The authors would like to express appreciation to the Faculty of Civil Engineering, Nanjing Forestry University for providing the laboratory.

\section{References}

[1] M. Åstrand, E. Jakobsson, M. Lindfors, and J. Svensson, “A system for underground road condition monitoring," International Journal of Mining Science and Technology, vol. 30, no. 3, pp. 405-411, 2020.

[2] J. D. Qiu, L. Luo, X. B. Li, D. Li, Y. Chen, and Y. Luo, "Numerical investigation on the tensile fracturing behavior of rockshotcrete interface based on discrete element method," International Journal of Mining Science and Technology, vol. 30, no. 3, pp. 293-301, 2020.

[3] X. M. Sun, C. W. Zhao, Y. Zhang, F. Chen, S. Zhang, and K. Zhang, "Physical model test and numerical simulation on the failure mechanism of the roadway in layered soft rocks," International Journal of Mining Science and Technology, vol. 31, no. 2, pp. 291-302, 2021.

[4] M. Feinendegen, M. Ziegler, G. Spagnoli, T. Fernández-Steeger, and H. Stanjek, "A New Laboratory Test to Evaluate the Problem of Clogging in Mechanical Tunnel Driving with EPB-Shields," in Rock Mechanics in Civil and Environmental Engineering, pp. 429-432, CRC Press, 2010.

[5] M. Feinendegen, M. Ziegler, G. Spagnoli, and T. FernándezSteeger, "Evaluation of the clogging potential in mechanical tunnel driving with EPB-shields," in Proceedings of the 15th European Conference on Soil Mechanics and Geotechnical Engineering, Athens, 2011.

[6] F. Hollmann and M. Thewes, "Assessment method for clay clogging and disintegration of fines in mechanised tunnelling," Tunnelling and Underground Space Technology, vol. 37, pp. 96-106, 2013.

[7] L. Qiu, D. Song, Z. Li, B. Liu, and J. Liu, "Research on AE and EMR response law of the driving face passing through the fault," Safety Science, vol. 117, pp. 184-193, 2019.

[8] R. Zumsteg and A. M. Puzrin, "Stickiness and adhesion of conditioned clay pastes," Tunnelling and Underground Space Technology, vol. 31, pp. 86-96, 2012.

[9] A. K. Basmenj, M. Ghafoori, A. Cheshomi, and Y. K. Azandariani, "Adhesion of clay to metal surface; normal and tangential measurement," Geomechanics \& Engineering, vol. 10, no. 2, pp. 125-135, 2016.

[10] U. Burbaum and I. Sass, "Physics of adhesion of soils to solid surfaces," Bulletin of Engineering Geology and the Environment, vol. 76, no. 3, pp. 1097-1105, 2017.

[11] L. Qiu, Z. Liu, E. Wang, X. He, J. Feng, and B. Li, "Early-warning of rock burst in coal mine by low-frequency electromagnetic radiation," Engineering Geology, vol. 279, p. 105755, 2020.

[12] C. D. Su, J. D. Qiu, Q. H. Wu, and L. Weng, "Effects of high temperature on the microstructure and mechanical behavior of hard coal," International Journal of Mining Science and Technology, vol. 30, no. 5, pp. 643-650, 2020.

[13] Y.-g. Zhang, J. Qiu, Y. Zhang, and Y. Wei, “The adoption of ELM to the prediction of soil liquefaction based on CPT," Natural Hazards, vol. 107, no. 1, pp. 539-549, 2021.

[14] Y. Zhang, Y. Xie, Y. Zhang, J. Qiu, and S. Wu, “The adoption of deep neural network (DNN) to the prediction of soil liquefaction based on shear wave velocity," Bulletin of Engineering Geology and the Environment, vol. 80, pp. 50535060, 2021.

[15] Y. Zhao, A. Taheri, M. Karakus, Z. Chen, and A. Deng, "Effects of water content, water type and temperature on the rheological behaviour of slag-cement and fly ash-cement paste backfill," International Journal of Mining Science and Technology, vol. 30, no. 3, pp. 271-278, 2020.

[16] Y. Zhang, J. Qiu, Y. Zhang, and Y. Xie, “The adoption of a support vector machine optimized by GWO to the prediction of soil liquefaction," Environmental Earth Sciences, vol. 80, no. 9, 2021.

[17] T. Qiu, C. Liu, X. Zhong, and Y. Zhu, "Experimental research on the impact of temperature on the adhesion characteristics of soil-structure interface," Geofluids, vol. 2020, 6675579 pages, 2020.

[18] G. Spagnoli, H. Stanjek, and M. Feinendegen, "Electrical manipulation of the clogging properties of ypresian and boom 
clays," Environmental \& Engineering Geoscience, vol. 20, no. 1, pp. 99-108, 2014.

[19] R. Zumsteg, A. M. Puzrin, and G. Anagnostou, "Effects of slurry on stickiness of excavated clays and clogging of equipment in fluid supported excavations," Tunnelling and Underground Space Technology, vol. 58, pp. 197-208, 2016.

[20] C. Qiu, Q. Zhang, S. Yan, and Y. Ji, "Experimental study of adhesion of clay," Rock and Soil Mechanics, vol. 38, no. 5, pp. 1267-1272, 2017.

[21] W. Drost-Hansen, "Structure of water near solid interfaces," Industrial \& Engineering Chemistry, vol. 61, no. 11, pp. 1047, 1969.

[22] J. Zhang, "Surfaces and interactions between interfaces," Journal of Jiangsu Institute of Technology, vol. 1984, no. 4, pp. 105$118,1984$. 